\title{
Simultaneous triple stent-by-stent deployment following endobiliary radiofrequency ablation for malignant hilar biliary obstruction
}
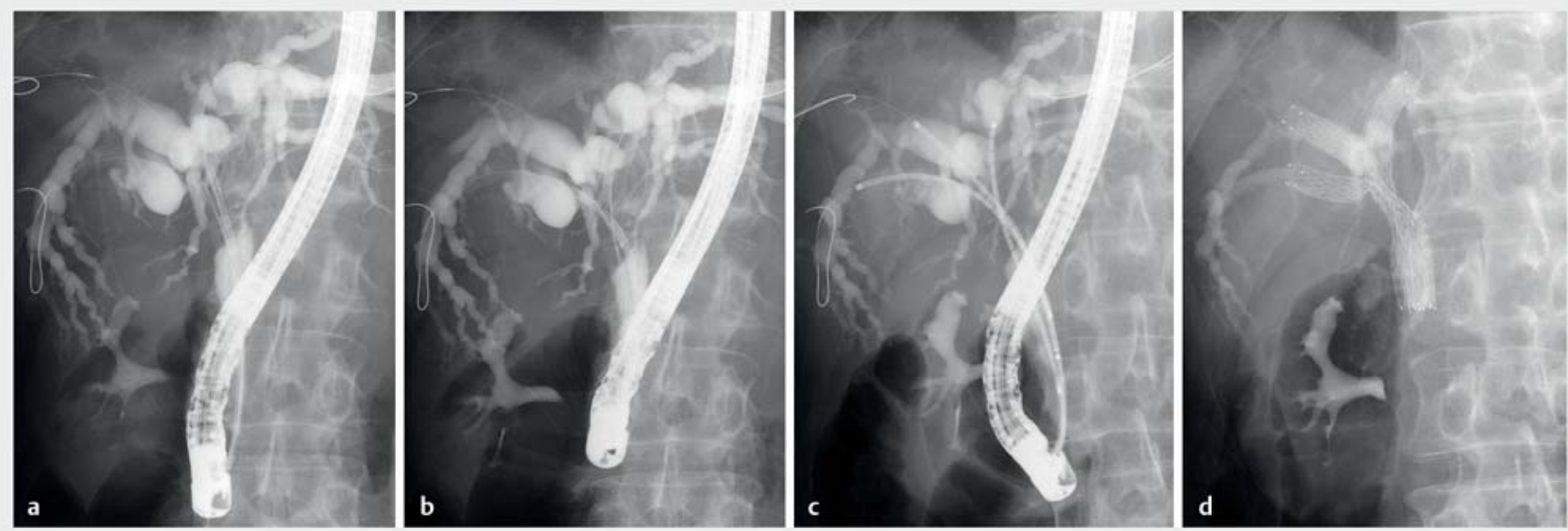

- Fig. 1 Triple stent-by-stent deployment. a, b After three guidewires were inserted across the Bismuth type IIla stricture, radiofrequency ablation was performed to the left and right hepatic duct strictures. $\mathbf{c}$ Three metal stent delivery systems were simultaneously introduced to the left, right posterior, and right anterior hepatic ducts. $\mathbf{d}$ The stents were released and placed in a stent-by-stent manner with their distal ends at the same level.

The simultaneous triple stent-by-stent (SBS) technique can prevent failure of the third stent insertion for trisectoral metal stenting in patients with malignant hilar biliary obstruction (MHBO) [1, 2] However, simultaneous insertion of three stent delivery systems is often challenging, especially for tight strictures. Endobiliary radiofrequency ablation (RFA), which can prolong stent patency in $\mathrm{MHBO}$ [3], renders the stricture and tumor degenerative [4], resulting in decreased tightness of the stricture. Here, we describe an initial case of simultaneous triple SBS deployment following endobiliary RFA for unresectable MHBO.

A 78-year-old man developed obstructive jaundice because of Bismuth type Illa MHBO. As diameter of the common bile duct was large, we chose the triple SBS method. After placement of three guidewires into the left hepatic duct (LHD), anterior branch of the right hepatic duct (a-RHD), and posterior branch of the RHD ( $p-R H D$ ), the RFA catheter (Habib EndoHPB catheter; Boston Scientific, Marlborough, Massachusetts, USA) was introduced over the LHD guidewire, and

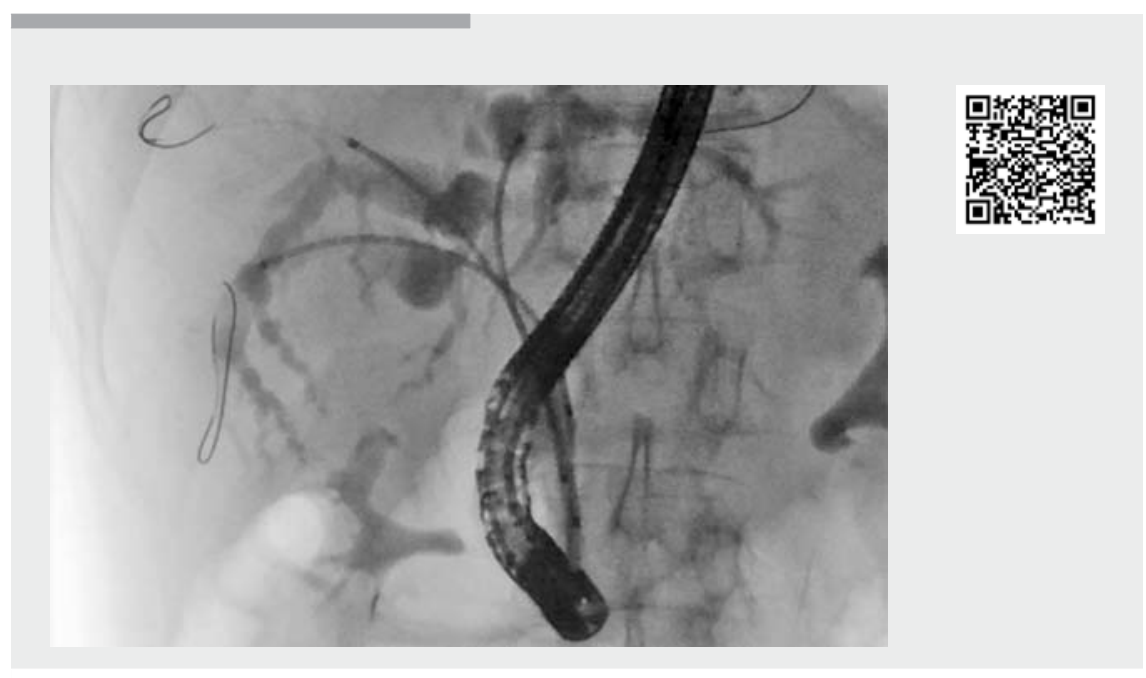

Video 1 Simultaneous triple stent-by-stent deployment following endobiliary radiofrequency ablation in a patient with high-grade malignant hilar biliary obstruction.

the stricture of the LHD was subsequently ablated for 90 seconds at $7 \mathrm{~W}$ (VIO300 D generator; ERBE Elektromedizin $\mathrm{GmbH}$, Tübingen, Germany). Then, the stricture of the RHD was also ablated over the P-RHD guidewire using the same settings. After RFA, three metal stents (Zeo
Stent V; Zeon Medical, Tokyo, Japan) were simultaneously introduced and passed smoothly through the stricture. Finally, the stents were released and placed in the order LHD, p-RHD, a-RHD ( $\triangleright$ Fig. 1, $\triangleright$ Video 1). All stents used were $8 \mathrm{~mm}$ in diameter and $80 \mathrm{~mm}$ in length. 
The patient's symptoms improved immediately, with no adverse events.

Endobiliary RFA, which can help prolong the patency of metal stents in patients with $\mathrm{MHBO}$, may also be useful for the simplification of simultaneous insertion of delivery systems.

Endoscopy_UCTN_Code_TTT_1AR_2AZ

\section{Competing interests}

Dr. Inoue has received honoraria from Boston Scientific Japan and Japan Lifeline Co., Ltd. All other authors declare that they have no conflict of interest.

The authors

Tadahisa Inoue, Rena Kitano, Mayu Ibusuki, Yuji Kobayashi, Kiyoaki Ito, Masashi Yoneda Department of Gastroenterology, Aichi Medical University, Aichi, Japan
Corresponding author

Tadahisa Inoue, MD, PhD

Department of Gastroenterology, Aichi Medical University, 1-1 Yazakokarimata, Nagakute, Aichi 480-1195, Japan

Fax: +81-561-633208

tinoue-tag@umin.ac.jp

\section{References}

[1] Sekine M, Fujiwara J, Mashima H. A novel method of triple stenting in patients with malignant hilar biliary obstruction: triple stenting abreast method. Endoscopy 2020. doi:10.1055/a-1108-1337

[2] Inoue T, Ito K, Yoneda M. Simultaneous triple side-by-side metal stent deployment for malignant hilar biliary obstruction. Dig Endosc 2020; 32: e65-e66

[3] Inoue T, Ibusuki M, Kitano R et al. Endobiliary radiofrequency ablation combined with bilateral metal stent placement for malignant hilar biliary obstruction. Endoscopy 2020. doi:10.1055/a-1133-4448

[4] Larghi A, Rimbaș M, Tringali A et al. Endoscopic radiofrequency biliary ablation treatment: a comprehensive review. Dig Endosc 2019; 31: 245-255
Bibliography

Endoscopy 2021; 53: E162-E163

DOI 10.1055/a-1224-3698

ISSN 0013-726X

published online 20.8.2020

(c) 2020. Thieme. All rights reserved.

Georg Thieme Verlag KG, Rüdigerstraße 14,

70469 Stuttgart, Germany

\section{ENDOSCOPY E-VIDEOS}

https://eref.thieme.de/e-videos

口回 Endoscopy E-Videos is a free

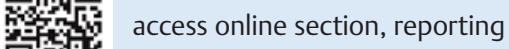
靣: on interesting cases and new techniques in gastroenterological endoscopy. All papers include a high quality video and all contributions are freely accessible online.

This section has its own submission website at https://mc.manuscriptcentral.com/e-videos 